\title{
In vitro induction of hairy root from isoflavones-producing Korean wild anownot Pueraria lobata
}

\author{
Soojung Kim $\cdot$ Min-Seok Cha $\cdot$ Eunji Lee $\cdot$ Inhye Kim $\cdot$ Jung Eun Kwon $\cdot$ Se Chan Kang $\cdot$ Tae-Ho Park
}

Received: 19 September 2012 / Accepted: 21 September 2012

(C) Korean Society for Plant Biotechnology

\begin{abstract}
Pueraria lobata is a perennial legume plant, widely distributed in the countries of East Asia. It is a medicinally important leguminous plant and produces various isoflavones such as puerarin, daidzein etc which have potential for preventing several chronic diseases including osteoporosis, cardiovascular disease and cancer. In this study, we tried to induce hairy roots in vitro from Korean wild arrowroot $P$. lobata and investigated the effects of hormones and light conditions. Initially leaf and stem segments were infected with Agrobacterium rhizogenes and incubated in different conditions. Hairy roots were induced from only stem segments and the induction was best at dark condition and the presence of IBA during incubation. Secondary roots were also significantly much more induced at the dark condition than at the 16 hours light condition. Among plant growth regulators of auxin, IBA was best for secondary root formation while 2,4-D, IAA and NAA produced callus or less hairy roots. The presence of the foreign gene rolC transferred by $A$. rhizogenes that plays a major role in hairy root induction was confirmed by PCR. The accumulation of isoflavones such as puerarin and daidzin was also confirmed. These results will facilitate mass production of hairy root and can be used for the production of functional substances from wild arrowroots.
\end{abstract}

S. Kim • M.-S. Cha $\cdot$ E. Lee · T.-H. Park $(\bowtie)$

Department of Horticulture, Daegu University, Gyeongsan 712-714, Republic of Korea

e-mail: thzoo@daegu.ac.kr

I. Kim

Functional Food \& Nutrition Division, National Academy of Agricultural Science, RDA, Suwon 441-853, Republic of Korea

J. E. Kwon · S. C. Kang

Department of Life Science, Gachon University, Seongnam

461-701, Republic of Korea

\section{Introduction}

The genus Pueraria is a perennial legume plant widely distributed in tropical and subtropical countries of East Asia and one of the oldest medicinal plants in Korea, China and Japan (Chen and Li 2007; Kim et al. 2009). These plants possess estrogen-like effects and have been used for the treatment of angina pectoris, hypertension, deafness, optic nerve and atrophy and as antipyretic, antidiarrheic, diaphoretic and antiemetic substances (Kinjo et al. 1987; Sato et al. 1992; Thiem 2003; Cherdshewasart et al. 2007). One of the genus Pueraria, P. lobata commonly called arrowroot or kudzu grows in Korea and is a Korean indigenous herb with the local name of 'Chihk'. Its tuberous root yields phenolic compounds, various isoflavonoids of high antioxidant properties such as daidzin, daidzein, genistin, and puerarin (Kinjo et al. 2000; Chansakaow et al. 2000; Kim et al. 2003; Pandey et al. 2007). The contents of the isofavonoids in the tuber are variable due to environmental conditions depending on the regions and seasons resulting different quality of tubers (Pappert et al. 2000; Cherdshewasart and Sriwatcharakul 2008) and phenolic compounds in medicinal plants have been reported to be unstable depending on factors like temperature, light and oxygen (Santos-Gomes et al. 2002). These problems led to establish plant tissue technologies to standardize a method for the production of such secondary metabolites.

Previous investigation of plant tissue cultures with the genus Pueraria was mostly limited to cell suspension and callus cultures. Boonsnongcheep et al. (2010) and Korsangruang et al. (2010) have developed a system of cell suspension culture and investigated its growth and isoflavonoid accumulation for P. candollei and Thanonkeo and Panichajakul (2006) have also reported on successful callus cultures of $P$. candollei while remarkable efforts have been reported on cell suspension cultures and enhancement of isoflavonoid accumulation for P. tuberosa (Vaishnav et al. 2006; Goyal 
and Ramawt 2007, 2008; Rathore and Shekhawat 2009). Moreover, Sharma et al. $(2009,2011)$ tried to scale up production of isoflavonoids in cell suspension cultures of $P$. tuberosa using a bioreactor. For P. lobata, a few results related to both tissue culture and isoflavone production were reported (Barbara 2003; Thiem 2003; Reppert et al. 2008). In addition to these, hairy root culture was used to improve isoflavonid production from $P$. candollei (Udomsuk et al. 2011) and P. phaseoloides (Shi and Kintzios 2003) as the induction of a stable and high rate of secondary metabolite production have been reported using hairy roots (Giri and Narasu 2000). Hwang (2006) also reported that hairy roots obtained through the transformation of higher plants using Agrobacterium rhizogenes produced various higher amounts of secondary metabolites than normal fieldgrown plants did. This technology has successfully been applied to other plant species (Bonhomme et al. 2000; Villalobos-Amador et al. 2002; Limpens et al. 2004; Bulgakov et al. 2005; Crane et al. 2006; Ko et al. 2007). The technology in which plant tissue culture is combined with hairy root induction has not been developed for $P$. lobata, especially Korean wild arrowroot although it has advantages for the production of secondary metabolites. In the present study, therefore, we set up a system of hairy root induction and culture and investigate the effects of plant growth regulators and light conditions for Korean wild arrowroot (Chihk), P. lobata. In addition to these, we compared the accumulation of isoflavones in the produced hairy root with that in tubers of Korean wild arrowroot.

\section{Material and methods}

\section{Plant materials}

Two different lines of Korean wild arrowroot, $P$. lobata collected in Mungyeong and Daejeon early spring were used. The collected plants were planted to clay pots and maintained in a greenhouse at Daegu University. When the plants were sprouted, stem and leaf segments were dissected. Twelve $0.5-1 \mathrm{~cm}$ long stem segments and twelve $0.5 \mathrm{~cm}$ x $0.5 \mathrm{~cm}$ leaf segments from two collected lines were used. They were surface-sterilized with $70 \%$ ethanol for 2 minutes and commercial bleach containing $1.5 \%$ sodium hypochlorite for 20 minutes and rinsed four times in sterile distilled water.

Hairy root induction and culture

A single strain of $A$. rhizogenes (KCTC2744), which were kindly provided by Korean Collection for Type Culture (KCTC), were used to infect two $P$. lobata lines. The strain was grown in $100 \mathrm{ml} \mathrm{NB}$ medium and collected by the centrifugation at 3,200 rpm for 10 minutes, followed by resuspension in growth regulator-free liquid MS medium (Murashige and Skoog 1962) for inoculation. The stem and leaf segments excised from the greenhouse plant of two lines were infected by dipping into the inoculum and the infected explants were cultured on MS medium in the dark at $23 \pm 2^{\circ} \mathrm{C}$. After 48 hours of co-cultivation, the explants were transferred to $1 / 2 \mathrm{MS}$ medium with $500 \mathrm{mg}$ cefotaxime (CF)/L supplemented with or without $0.5 \mathrm{mg} / \mathrm{L}$ indole-3butyric acid (IBA) and cultured in the dark or in the 16 hours light and 8 hours dark condition. At 2-week intervals, infected segments were transferred to $1 / 2 \mathrm{MS}$ medium with 300 and $100 \mathrm{mg} \mathrm{CF} / \mathrm{L}$. Medium and light conditions were continuously identical to the initial treatment. When the hairy roots were induced, they were subcultured on $1 / 2$ MS medium containing $0.5 \mathrm{mg} / \mathrm{L} \mathrm{IBA}$ and cultured in the dark or in the 16 hours light and 8 hours dark condition for two weeks to investigate the effect of light condition on the induction of secondary roots from the primary hairy roots. In addition to these, transformed hairy roots of $P$. lobata were subcultured on $1 / 2$ MS medium supplemented with $0.5 \mathrm{mg} / \mathrm{L}$ of 2,4-dichlorophenoxy acetic acid (2,4-D), 1-naphthalene acetic acid (NAA), indole 3-butyric acid (IBA) and indole acetic acid (IAA) each and incubated in the dark at $23 \pm 2^{\circ} \mathrm{C}$ to examine the effect of different auxins.

\section{DNA isolation and PCR analysis}

Colonies of bacterial strain A. rhizogenes KCTC2744 and genomic DNA of transformed and untransformed plant materials were used to analyze whether or not induced roots contained hairy root induction gene. Genomic DNA was isolated from hairy roots and from the control roots frozen in liquid nitrogen by the method slightly modified from Doyle and Doyle (1990), Bousquet et al. (1990) and Park and Jones (2009). The polymerase chain reaction was used to confirm the presence of the rolC gene in the bacterial strain and roots. PCR experiments were performed using primers at the position 51-69 (5'-TGTGACAAGCAGCGA TGAG-3') and 550-532 (5'-GATTGCAAACTTGCACTCG3'), designed for the amplification of a $490 \mathrm{bp} \mathrm{rolC}$ fragment (Bonhomme et al. 2000). Samples for PCR reaction were subjected to 35 cycles of $30 \mathrm{sec}$ denaturation at $94^{\circ} \mathrm{C}$, $30 \mathrm{sec}$ annealing at $56^{\circ} \mathrm{C}$ and $1 \mathrm{~min}$ extension at $72^{\circ} \mathrm{C}$. Amplified DNAs were detected on $1 \%$ agarose gels. 
Isoflavones extraction and analysis

To analyze the accumulation of isoflavones (puerarin and daidzin) in the produced hairy root, tubers and callus of Korean wild arrowroot, two lines were used. The following reagents were used as standard substances: puerarin, P-5555 Sigma-Aldrich (MG, USA); and daidzin, D-30408 SigmaAldrich (MG, USA). An SIL-20A equipped with SPDM20A PDA and CTO-20A column oven (SHIMDZU Corp., Kyoto, Japan) was used for HPLC analysis. Data were analyzed using the attached software. The fractions were separated at $40^{\circ} \mathrm{C}$ on a ACE-121-2546 (Advanced Chromatography Technologies Corp., Aberdeen, Scotland) using a one-step linear gradient. Mobile phase A [water : acetic acid (100:1)] and B [water : acetonitrile : acetic acid (50: 50:1)] ratios where changed after 5 minutes from $7: 3$ to $3: 7$ for 40 minutes at a flow rate of $1.0 \mathrm{~mL} / \mathrm{min}$.

\section{Statistical analysis}

Counts of the stem segments at which hairy roots and secondary root were induced were made every week. To analyze the effects of each treatment, the number of stem segments and secondary roots scored six and two weeks after initial culture were analyzed using analysis of variance (ANOVA), respectively. After defining the effects of two or one factors and interactions between factors, Duncan's multiple-range test (DMRT) were applied to analyze the effects of each treatment.

\section{Results and discussion}

For setting up the system of hairy root induction and culture from Korean wild arrowroot P. lobata, stem and leaf segments of two lines collected from two different regions were infected with $A$. rhizogenes strain KCTC2744 as the pathogen has been known to be able to induce hairy roots due to its root-inducing plasmid (Bonhomme et al. 2000; Villalobos-Amador et al. 2002; Bulgakov et al. 2005; Crane et al. 2006; Kim et al. 2010). Continuous culture of infected stem segments generated hairy roots while leaf segments did not (Fig. 1A and 1B) and secondary roots were successfully induced and elongated by subculture of the primary hairy roots (Fig. 1C and 1D).

For the investigation of effects of IBA and light on hairy root induction, 12 infected stem explants of each line were incubated at different conditions: 1) continuous dark with $0.5 \mathrm{mg} / \mathrm{L}$ IBA in the medium, 2) continuous dark without IBA in the medium, 3) 16/8 hours light/dark with $0.5 \mathrm{mg} / \mathrm{L}$ IBA in the medium and 4) $16 / 8$ hours light/ dark without IBA in the medium as each condition was applied to induce or culture hairy roots in Pueraria species (Thiem 2003; Reppert et al. 2008; Rathore and Shekhawat 2009; Udomsuk et al. 2011) and other plant species (Ko et al. 2007; Ono et al. 2012; Swain et al. 2012). The data on hairy root induction scored six weeks after initial incubation were used for statistical analysis. As shown in Table 1, the efficiency of hairy root induction on the dark condition and the supplement of $0.5 \mathrm{mg} / \mathrm{L} \mathrm{IBA}$ in the medium was $91.7 \%$ and the number of explants with the induced hairy root was significantly higher than those on other treatments. Successive experiment for the induction of secondary roots resulted that the continuous dark condition was much better than the 16 hours light and 8 hours dark condition (Table 2) and average numbers of the secondary roots were 32.5 and 14.6, respectively. In most cases of experiments for hairy root induction, the infected explants were transferred to fresh medium with reduced antibiotics and without plant hormones every two or three weeks and routinely incubated at the dark condition or under continuous light for 16 hours (Crane et al. 2006; Ko et al. 2007; Prasain et al. 2007; Kim et al. 2010; Udomsuk et al. 2011). However, the effects of auxin-type hormones and light conditions were not investigated for the initial induction of hairy roots from $P$. lobata. The results obtained

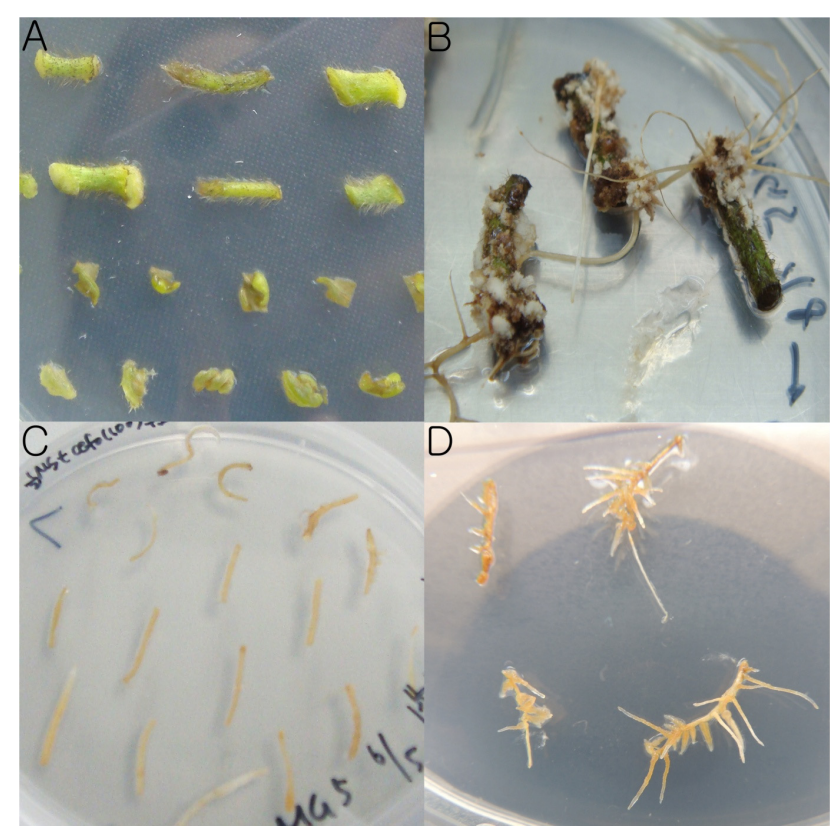

Fig. 1 Hairy root induction of Korean wild arrowroot, P. lobata. A: Stem and leaf segments grown in root induction medium, B: Hairy root induced from stem segments after four weeks of culture, C: Hairy root explants, D: Secondary roots initiated from hairy root explants after two weeks of subculture 
Table 1 Effects of IBA and light conditions on hairy root induction from stem segment of $P$. lobata in 1/2 MS medium six weeks after initial incubation

\begin{tabular}{ccccc}
\hline $\begin{array}{c}\text { Light } \\
\text { condition }\end{array}$ & $\begin{array}{c}\text { IBA } \\
(0.5 \mathrm{mg} / \mathrm{L})\end{array}$ & $\begin{array}{c}\text { Number of incubated } \\
\text { explants }\end{array}$ & $\begin{array}{c}\text { Number of explants with } \\
\text { hairy } \text { root }^{1}\end{array}$ & $\begin{array}{c}\text { Efficiency of hairy root } \\
\text { induction }(\%)\end{array}$ \\
\hline Dark & Presence & 24 & $11 \pm 1.4^{\mathrm{a}}$ & 91.7 \\
Dark & Absence & 24 & $2 \pm 0^{\mathrm{b}}$ & 16.7 \\
Light & Presence & 24 & $2 \pm 2.8^{\mathrm{b}}$ & 16.7 \\
Light & Absence & 24 & $0.5 \pm 0.7^{\mathrm{b}}$ & 4.2 \\
\hline
\end{tabular}

${ }^{1}$ The values represent mean \pm standard deviation. Mean values with a different letter are significantly different at $\mathrm{P}=0.05$ by DMRT.

Table 2 Effect of light condition on the induction of secondary roots from the primary roots of $P$. lobata in $1 / 2$ MS medium containing $0.5 \mathrm{mg} / \mathrm{L}$ IBA two weeks after subculture

\begin{tabular}{ccc}
\hline Light condition & Number of incubated explants & Number of secondary roots \\
\hline Dark & 19 & $32.5 \pm 5.7^{\mathrm{a}}$ \\
Light & 25 & $14.6 \pm 3.8^{\mathrm{b}}$ \\
\hline
\end{tabular}

${ }^{1}$ The values represent mean \pm standard deviation. Mean values with a different letter are significantly different at $\mathrm{P}=0.05$ by $\mathrm{DMRT}$.

in this study could conclude that the supplement of IBA during medium refreshment and the incubation under the continuous dark condition during the primary hairy root induction and secondary root induction were effective (Table 1 and 2). Additionally, plant growth regulators of auxin including IAA, IBA and NAA were often tested to accelerate the growth of roots, when induced hairy roots or adventitious roots were subcultured (Thiem 2003; Reppert et al. 2008; Uddin et al. 2012). We also tried to select the optimal plant hormone of auxin for secondary root formation and growth. As shown in Fig. 2, both IBA and IAA formed secondary roots, but IBA was better than IAA on the number and growth of secondary roots. 2,4-D and NAA mainly formed callus. These results were contradictory to those of some other researches. Thiem (2003) reported that IAA is clearly more effective in promoting root induction from the regenerated shoots than NAA or IBA and Reppert et al. (2008) used NAA for root suspension culture. However, IBA has commonly been used in several plant species and was identified as the best auxin-type hormone for root induction and root growth (Verma et al. 2002; Ko et al. 2007; Rathore et al. 2009; Swain et al. 2012; Uddin et al. 2012).

A. rhizogenes is a plant pathogen capable of inducing hairy roots in a variety of plants (Cardarelli et al. 1987). Therefore this bacterium has often been used to induce hairy roots. The integration of the root-inducing plasmid into the plant genome was successfully performed and confirmed using hairy root induction-related genes in various plant species such as Atropa belladonna (Bonhomme et al. 2000), the genus Pinus (Villalobos-Amador et al. 2002),

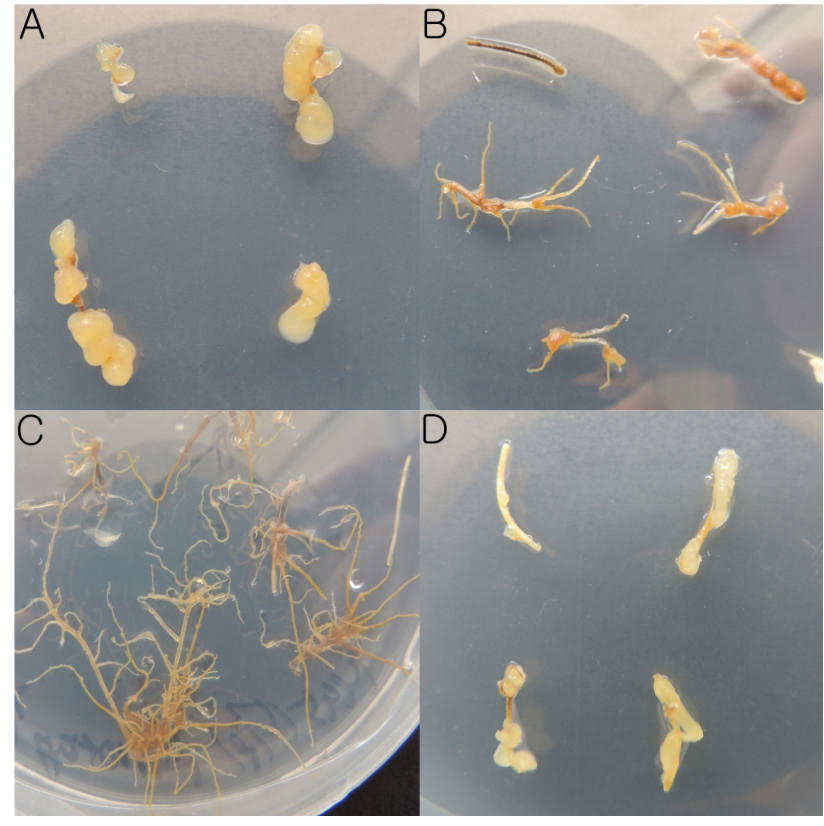

Fig. 2 Effect of different plant growth regulators of auxin on secondary root formation. A: $0.5 \mathrm{mg} / \mathrm{L} 2,4-\mathrm{D}, \mathrm{B}: 0.5 \mathrm{mg} / \mathrm{L} \mathrm{IAA}$, C: $0.5 \mathrm{mg} / \mathrm{L}$ IBA, D: $0.5 \mathrm{mg} / \mathrm{L}$ NAA

Pueraria phaseoloides (Shi and Kintzios 2003), Medicago truncatula (Limpens et al. 2004; Crane et al. 2006), Eritrichium sericeum and Lithospermum erythrorhizon (Bulgakov et al. 2005), Panax ginseng (Ko et al. 2007) etc. In this study, stem explants of two different lines of $P$. lobata were infected with the $A$. rhizogenes strain KTCT2744. After hairy roots were induced from the infected stem explants, DNA was isolated from both transformed and untransformed roots. PCR analysis (Fig. 3) showed that the $A$. 


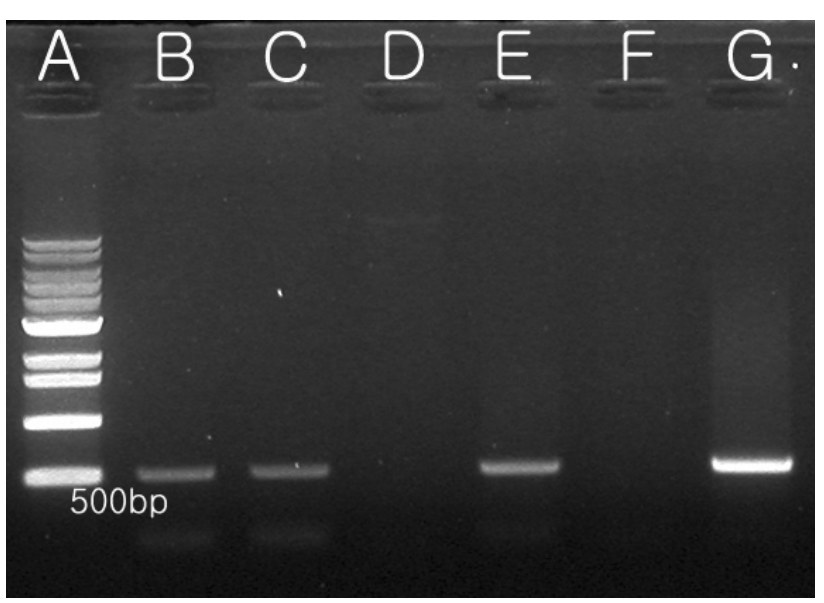

Fig. 3 PCR amplified DNA fragments of the rolC gene. Lane A: Marker ladder, lanes B-C: DNA from A. rhizogenes KCTC2744 as positive controls, lane D: DNA from the intact roots of $P$. lobata line I as a negative control, lane E: DNA from hairy roots of $P$. lobata line I incubated with $A$. rhizogenes KCTC 2744, F: DNA from the intact roots of $P$. lobata line II as a negative control, G: DNA from hairy roots of $P$. lobata line II incubated with $A$. rhizogenes KCTC2744 rhizogenes strain and the transformed lines contained the rolC gene (lanes B, C, E and G) and no band was observed for the untransformed roots (lanes D and F). Amplification with the rolC primers showed bands around the $500 \mathrm{bp}$ size marker. The size of the bands is coincident with the expected size of rolC. This result indicated that the hairy root inducible gene from $A$. rhizogenes has properly been integrated to the genome of $P$. lobata.

To investigate a possibility of producing functional substances from the produced hairy roots, isoflavones such as puerarin and daidzin were analyzed using a HPLC method in two different lines of Korean wild arrowroot. As shown in Table 3 and Fig. 4, both of the substances were detected in the hairy root. The amounts of them were less than those in wild tubers. However, the accumulation of isoflavones in tissue-cultured Pueraria has been reported to be variable depending on the treatment of abiotic and biotic elicitors (Korsangruang et al. 2010; Udomsuk et al. 2011). Therefore, the accumulation of isoflavones in hairy root could be

Table 3 Isoflavone contents in different tissues of Korean wild arrowroot

\begin{tabular}{|c|c|c|c|c|}
\hline & \multicolumn{2}{|c|}{ Line I } & \multicolumn{2}{|c|}{ Line II } \\
\hline & Puerarin & Daidzin & Puerarin & Daidzin \\
\hline Tuber & 1.170 & 0.720 & 0.660 & 0.270 \\
\hline Callus & 0.041 & 0.006 & 0.002 & 0.004 \\
\hline Hairy root & 0.382 & 0.026 & 0.310 & 0.021 \\
\hline
\end{tabular}

Puerarin and daidzin content are given in milligram per gram dry weight.
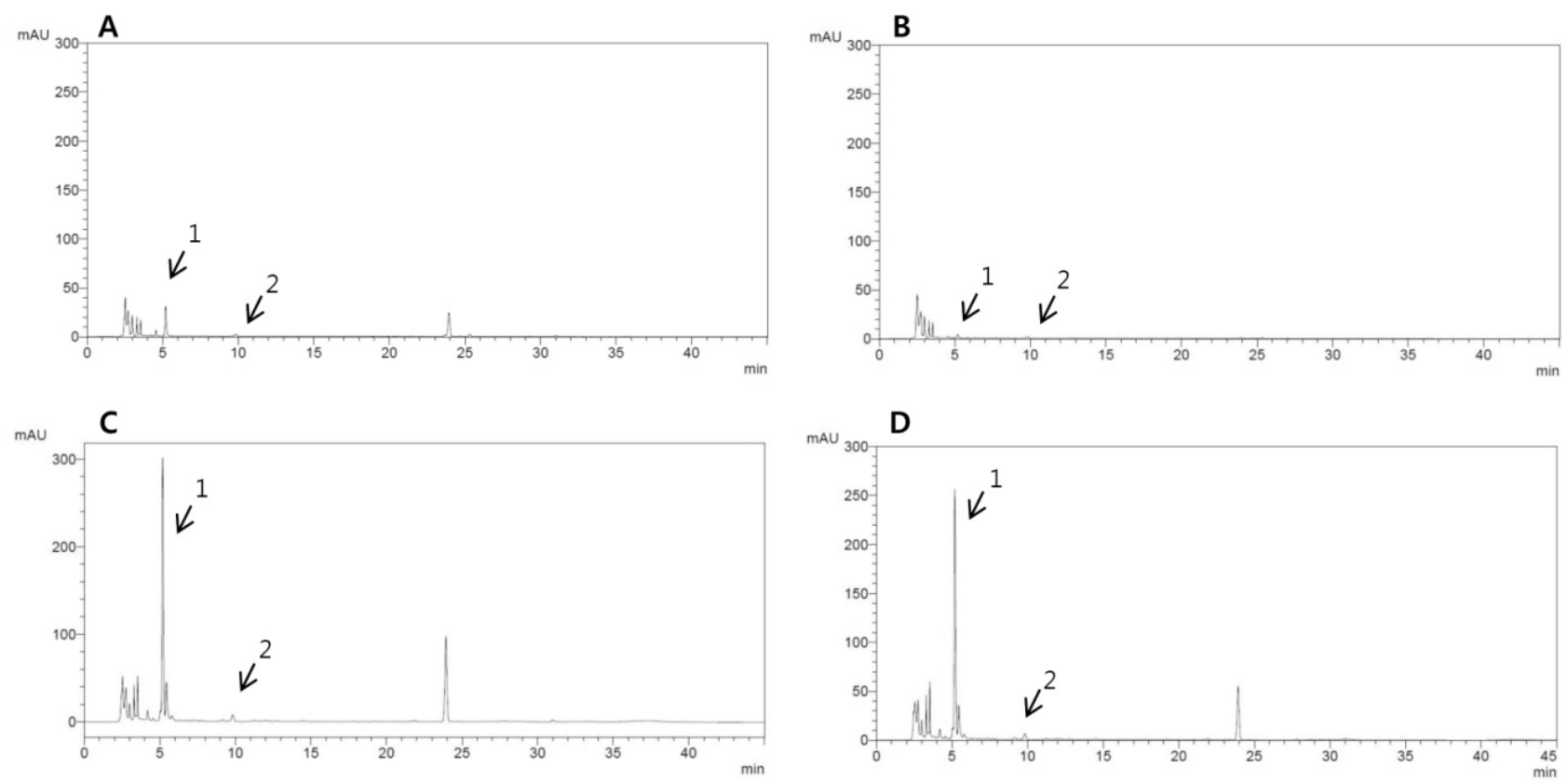

Fig. 4 HPLC-PDA analysis of puerarin (1) and daidzin (2) from callus and hairy root of Korean wild arrowroot. A: Callus of line I B: Callus of line II C: Hairy root of line I D: Hairy root of line II 
expected to be enhanced and the system of hairy root induction and culture developed in this study can be applied.

In conclusion, we developed an in vitro system for hairy root induction and secondary root formation from Korean wild arrowroot, $P$. lobata. The addition of IBA to the culture media remarkably improved hairy root induction and secondary root formation under the continuous dark condition. The accumulation of puerarin and daidzin in the hairy root was also confirmed. These root induction and growth systems will facilitate the mass production of arrowroots that could be used for a wide variety of purposes such as an extraction of functional substances and a development of functional foods and cosmetics.

\section{Acknowledgements}

This study was carried out with the support of "Cooperative Research Program for Agricultural Science \& Technology Development (Project No. PJ008398)", Rural Development Administration, Republic of Korea and supported by the Daegu University Research Scholarship Grants.

\section{References}

Barbara T (2003) In vitro propagation of isoflavone-producting Pueraria lobata (Willd.) Ohwi. Plant Sci 165:1123-1128

Bonhomme V, Laurain-Mattar D, Lacoux J, Fliniaux M-A, Jacquin-Dubreuil A (2000) Tropane alkaloid production by hairy roots of Atropa belladonna obtained after transformation with Agrobacterium rhizogenes 15834 and Agrobacterium tumefaciens containing $\operatorname{rol} A, B, C$ genes only. J Biotechnol 81:151-158

Boonsnongcheep P, Korsangruang S, Soonthornchareonnon N, Chintapakorn Y, Saralamp P, Prathanthurarug S (2010) Growth and isoflavonoid accumulation of Pueraria candollei var. candollei and $P$. candollei var. mirifica cell suspension cultures. Plant Cell Tiss Cult 101:119-126

Bousquet J, Simon L, Lalonde M (1990) DNA amplification from vegetative and sexual tissues of trees using polymerase chain reaction. Can J For Res 20:254-257

Bulgakov VP, Veselova MV, Tchernoded GK, Kiselev KV, Fedoreyev SA, Zhuravlev YN (2005) Inhibitory effect of the Agrobacterium rhizogenes rolC gene on rabdosiin and rosmarinic acid production in Eritrichium sericeum and Lithospermum erythrorhizon transformed cell cultures. Plant 221:471-478

Cardarelli M, Mariotii D, Pomponi M, Spanó L, Capone I, Costantino P (1987) Agrobacterium rhizogenes T-DNA gene capable of inducting hairy root phenotype. Mol Gen Genet 209:475-480

Chansakaow S, Ishikawa T, Sekine K, Okada M, Higushi Y, Kudo
M, Chaichantipyuth C (2000) Isoflavonoids from Pueraria mirifica and their estrogenic activity. Planta Med 66: 572-574

Chen G, Li L (2007) Nutrient consumption and production of isoflavones in bioreactor cultures of Pueraria lobata (Willd). J Environ Biol 28:321-326

Cherdshewasart W, Sriwatcharakul S (2008) Metabolic activation promotes estrogenic activity of the phytoestrogen-rich plant. Maturitas 59:128-136

Cherdshewasart W, Subtang S, Dahlan W (2007) Major isoflavonoid contents of the phytoestrogen rich-herb Pueraria mirifica in comparison with Pueraria lobata. J Pharm Biomed Anal 43:428-434

Crane C, Wright E, Dixon RA, Wang Z-Y (2006) Transgenic Medicago truncatula plants obtained from Agrobacterium tumefaciens-transformed roots and Agrobacterium rhizogenestransformed hairy roots. Planta 223:1344-1354

Doyle JJ, Doyle JL (1990) Isolation of plant DNA from fresh tissue. Focus 12:13-15

Giri A, Narasu ML (2000) Transgenic hairy roots: recent trends and applications. Biotechnol Adv 18:1-22

Goyal S, Ramawat KG (2007) Effect of chemical factors on production of isoflavones in Pueraria tuberose (Roxb.ex. Willd.) DC suspension culture. Indian J Exp Biol 45:10631067

Goyal S, Ramawat KG(2008) Increased isoflavonids accumulation in cell suspension cultures of Pueraria tuberose by elicitors. Indian J Biotechnol 7:378-382

Hwang SJ (2006) Baicalin production in transformed hairy root clones of Scutellaria baicalensis. Biotechnol Bioprocess Eng 11:849-853

Kim C, Shin S, Ha H, Kim JM (2003) Study of substance changes in flowers of Pueraria thunbergiana Benth. Duing storage. Arch Pharm Res 26:210-213

Kim D-K, Jang DS, Kim JS, Kim J-H (2009) Genetic variations and phylogenetic relationship of and Pueraria lobata Ohwi (Fabaceae) and related taxa by RAPD makers. Korean J Plant Res 22:446-453

Kim JS, Oh EJ, Lee SK (2010) Influence of different strains of Agrobacterium rhizogenes on hairy root induction andn rosmarinic acid production in Agastache rugosa Kuntze. Korean J Plant Res 23:14-18

Kinjo J-E, Furusawa J-I, Baba J, Takeshita T, Yamasaki M, Nohara T (1987) Studies on the constituents of Pueraria lobata. III: Isoflavonoids and related compounds in the roots and the voluble stems. Chem Pharm Bull 35:4846- 4850

Kinjo J, Ikeda T, Okawa M, Udayama M, Hirakawa T, Shii Y, Nohara T (2000) Hepatoprotective and hepatotoxic activities of Soporadiol analogs on rat primary liver cell cultures. Biol Chem Bull 23:1118-1121

Ko SM, In DS, Chung H-J, Choi D-W, Liu JR (2007) Mass production of gain-of-function mutants of hair roots in Ginseng. J Plant Biotechnol 34:285-591

Korsangruang S, Soonthornchareonnon N, Chintapakorn Y, Saralamp P, Prathanturarug S (2010) Effects of abiotic and biotic elicitors on growth and isoflvonoid accumulation in 
Pueraria candollei var. candollei and P. candollei var. mirifica cell suspension cultures. Plant Cell Tiss Organ Cult 103: 333-342

Limpens E, Ramos J, Franken C, Raz V, Compaan B, Franssen H, Bisseling T, Geurts R (2004) RNA interference in Agrobacterium rhizogenes-transformed roots of Arabidopsis and Medicago truncatula. J Exp Bot 55:983-992

Murashige T, Skoog F (1962) A revised medium for rapid growth and bioassays with tobacco tissue culture. Physiol Plant 15:473-497

Ono NN, Bandaranayake PCG, Tian L (2012) Establishment of pomegranate (Punica granatum) hairy root cultures for genetic interrogation of the hydrolysable tannin biosynthetic pathway. Planta 236:931-941

Pandey N, Chaurasia JK, Tiwari OP, Triphati YB (2007) Antioxidant properties of different fractions of tubers from Pueraria tuberose Linn. Food Chem 105:219-222

Pappert RA, Hamrich JL, Donovan LA (2000) Genetic variation in Pueraria lobata (Fabaceae), an introduced, clonal, invasive plant of the southeastern United States. Am J Bot 87:12401245

Park T-H, Jones JDG (2009) A new resistance gene to powdery mildew identified in Solanum neorossii has been localized on the short arm of potato chromosome 6. Euphytica 166: 331-339

Prasain JK, Reppert A, Jones K, Moore DR, Barnes S, Lila MA (2007) Identification of isoflavones glycosides in Pueraria lobata cultures by tandem mass spectrometry. Phytochem Anal 18:50-59

Rathore MS, Shekhawat NS (2009) Micropropagation of Pueraria tuberose (Roxb. Ex Willd.) and determination of puerarin content in different tissues. Plant Cell Tiss Organ Cult 99:327-334

Reppert A, Yousef GG, Rogers RB, Lila MA (2008) Isolation of radiolabeled isoflavones from Kudzu (Pueraria lobata) root cultures. J Agric. Food Chem 56:7860-7865

Santos-Gomes PC, Seabra RM, Andrade PB, Fernandes-Ferreira M (2002) Phenolic antioxidant compounds produced by in vitro shoots of sage (Salvia officinalis L.). Plant Sci 162: 981-987

Sato T, Kawamoto A, Tamura A, Tatsumi Y, Fujii T (1992)
Mechanism of antioxidant action of pueraria glycoside (PG)-1 (an isoflavonoid) and mangiferin (a xanthonoid). Chem Pharm Bull 40:721-724

Sharma V, Goyal S, Ramawat KG (2009) Scale up production of isoflavonoids in cell suspension cultures of Pueraria tuberose grown in shake flasks and bioreactor. Eng Life Sci 9:267-271

Sharma V, Goyal S, Ramawat KG (2011) Increased puerarin biosynthesis during in vitro shoot formation in Pueraria tuberose grown in growtek bioreactor with aeration. Physiol Mol Biol Plants 17:87-92

Shi H.-P and Kintzios S (2003) Genetic transformation of Pueraria phaseoloides with Agrobacterium rhizogenes and puerarin production in hairy roots. Plant Cell Rep 21:1103-1107

Swain SS, Sabu L, Pal A, Barik D.P, Pradhan C, Chand P.K (2012) Hairy root cultures of butterfly pea (Clitoria ternatea L.): Agrobacterium $\times$ plant factors influencing transformation. World J Microbiol Biotechnol 28:729-739

Thanonkeo S, Panichajakul S (2006) Production of isoflavones, daidzein and genistein in callus cultures of Pueraria candollei Wall. Ex Benth. Var. mirifica. Songklanakarin J Sci Technol 28:45-53

Thiem B (2003) In vitro propagation of isolavone-producing Pueraria lobata (Willd.) Ohwi. Plant Sci 165:1123-1128

Uddin MR, Li X, Won OJ, Park SU, Pyon JY (2012) Herbicidal activity of phenolic compounds from hairy root cultures of Fagopyrum tataricum. Weed Res 52:25-33

Udomsuk L, Jarukamjorn K, Tanaka H, Putalun W (2011) Improved isoflavonoid production in Pueraria candollei hairy root cultures using elicitation. Biotechnol Lett 33: 369-374

Vaishnav K, Goyal S, Ramawat KG (2006) Isoflavonoids production in callus culture of Pueraria tuberose, the Indian kudzu. Indian J Exp Biol 44:1012-1017

Verma P, Singh D, Rahman L, Gupta MM, Banerjee S (2002) In vitro-studies in Plumbago zeylanica: rapid micropropagation and establishment of higher plumbagin yielding hairy root cultures. J Plant Physiol 159:547-552

Villalobos-Amador E, Rodriguez-Hernández G, Pérez-MolpheBalch E (2002) Organogenesis and Agrobacterium rhizogenesinduced rooting in Pinus maximarinezii Rzedowsky and $P$. pinceana Gordon. Plant Cell Rep 20:779-785 